iv) $\mathrm{He}$ /she should have a broad understanding of environmental processes and conservation, and therefore be able to draw on and develop the expertise of the team.

The function of the TEC should involve performing such duties as: helping to appoint the team, liaising with head teachers and their staff, coordinating the relationship between teacher and CEA, acting as consultant/ adviser to the group, coordinating policy, communicating with and coordinating the local community, keeping abreast of topical issues and publications as well as local organizations etc., fund-raising (possibly!), and all the time training the team by developing skills, discussing ideas and problems, and encouraging initiative. An attitude of adventure should he encouraged throughout.

\section{Finance}

The plan is to set up a team of keen unemployed naturalists (teachers, graduates, and others) to work with the primary schools in the (human) catchment area of Langtree School (a comprehensive school at Woodcote, Oxfordshire, England). The scheme will be relying very heavily on the Manpower Services Commission (MSC), from whom we have obtained the support for six part-time places. A charitable Trust is, however, being established to cover administrative and supervisory expenses and to provide a cushion against any political or MSC changes, so that donations will always be welcome.

\author{
STEPHEN R. HART \\ Hammonds Farm, Checkendon \\ Reading RG8 ONS, England, UK.
}

\title{
Leaf from a Graduate Student's Paper: Our Message about The Biosphere Evidently Sinking In*
}

I never really thought about The Biosphere until Polunin addressed our class. Though I had heard of The Biosphere before, I had never thought about how it encompasses our very life. I told some of my friends that we were drawing up some proposals about The Biosphere and were possibly going to get them published in an internationally read environmental journal. They scoffed and asked how I could think that they could take us, a bunch of idealistic college students, seriously about something as important as The Biosphere. I did not answer, but thought to myself about that Ben Franklin quote which was on the board the other day: 'They man who does things may make mistakes, but he never makes the biggest mistake of doing nothing.'

I kept thinking that they can go on studying their economics, political science, and business law, but that they will have to make the decision of whether to act or not someday. Clearly, education will have to play a key role if we are to save The Biosphere. We must learn to get along with The Biosphere, for it is our environment, our air, and our life-blood. If we do not modernize and rethink our environmental policies soon, it may become too late. Teaching the responsibilities and consequences of human occupance of The Biosphere is analogous to teaching people about their own homes.

If you do not maintain the condition of your home - its physical plant and family - it will soon start to degrade. Once degradation has started, new policies must be implemented quickly to stop failure of the structure of the house and its inhabiting family. A house is not a home without people living in it, just as The Biosphere is nothing without [plenty of] that indefinable thing we call life. I thought that point five of our proposal was very good: Upholding The Biosphere as sacred, as life itself is sacred, will serve to help Manking to save it.

\footnotetext{
* Kindly communicated by Professor Henryk Skolimowski, whose submission with his students on 'The Biosphere as Seen by Students from Ann Arbor, Michigan', was published late last year (Environmental Conservation, 10(4), p. 356, 1983).-Ed.
}

\section{International Conservation Conventions: Are They Being Implemented?}

The undersigned and Laura $H$. Kosloff are currently conducting investigations into the implementation of international conservation conventions. The 'implementation gap' is a well-recognized but inadequately studied phenomenon which seriously hampers conservation efforts. Information on whether, and if so how, international legal instruments for conservation are being implemented in individual countries has never, so far as we are aware, been collected or analyzed. The information or materials in which we are most interested includes:

- Copies or at least citations of any reports, memoranda, or papers, discussing the implementation of CITES, World Heritage, Ramsar, Western Hemisphere, as well as other international conventions and agreements dealing with habitats, species, or genetic resources. (This information can be general or specific with respect to a particular country.)

- Information on the specific national legislation implementing these conventions in individual countries, and on the legislation's strengths and weaknesses (in carrying out such implementation).
-Personal and organizational views on the implementation and effectiveness of particular conventions, their strengths and weaknesses, their particular advantages and drawbacks, and the politics of their adoption and implementation.

Any information which readers of Environmental Conservation may be able to provide will help us in understanding what is happening with the current body of international conventions, in what directions they can and should go in the future, and whether further conventions would be appropriate. Your cooperation would be greatly appreciated. Confidentiality can be maintained if desired. Please send any responses and pertinent information to the undersigned.

MARC C. TREXLER, Research Associate
International Union for Conservation of Nature
$\quad$ and Natural Resources (IUCN)
Avenue du Mont-Blanc
1196 Gland
Switzerland.

Marc C. Trexler, Research Associate and Natural Resources (IUCN)

1196 Gland

Switzerland. 